\title{
Turn Back Plagiarism! Budaya Organisasi Anti Plagiarism
}

\author{
Rohmatun Lukluk Isnaini \\ UIN Sunan Kalijaga Yogyakarta, Yogyakarta, Indonesia \\ Email: lukluk_isnaini@yahoo.com
}

\begin{abstract}
Abstrak
Tulisan ini bertujuan untuk mengetahui budaya organisasi antiplagiarisme di pascasarjana UIN Sunan Kalijaga Yogyakarta. Metode penelitian yang digunakan adalah penelitian kualitatif. Data diperoleh melalui wawancara, observasi, dan dokumentasi. Hasil penelitian menyebutkan pascasarjana di UIN Sunan Kalijaga Yogyakarta telah menegakkan budaya organisasi antiplagiarisme melalui 3 hal, yaitu artefak, espoused value/ enacted behavior dan asumsi dasar yang dipercaya. Artefak antiplagiarisme ditunjukkan pada stiker dan tempelan dinding yang berisi redaksi penolakan tindakan plagiarism yang dipasang ditempet-tempat strategis. Espoused valuel enacted behavior ditunjukkan melalui penyusunan student handbook dan pemberlakuan checker plagiarism pada karya tulis mahasiswa. Adapun tingkatan tertinggi pada budaya organisasi adalah asumsi yang menjadi dasar nilai antiplagiarisme adalah nilai-nilai penjabaran pancasila yang sangat menjunjung tinggi Hak Kekayaan Intelektual (HAKI).
\end{abstract}

Kata kunci: Plagiarisme, Antiplagiarisme, Budaya Organisasi.

\section{Turn Back Plagiarism! Anti Plagiarism Organizational Culture}

\begin{abstract}
This paper aims to determine the organizational culture of antiplagiarism in the postgraduate UIN Sunan Kalijaga Yogyakarta. The research method used is qualitative research. Data obtained through interviews, observation, and documentation. The results of the study state that postgraduate programs at UIN Sunan Kalijaga Yogyakarta have upheld antiplagiarism organizational culture through 3 things, namely artifacts, espoused value / enacted behavior and trusted basic assumptions. Antiplagiarism artifacts are shown on stickers and wall patches containing editorial rejection of plagiarism actions placed in strategic locations. Espoused value / enacted behavior was demonstrated through the preparation of the student handbook and the application of plagiarism checkers in student papers. The highest level in organizational culture is the assumption that is the basis of the value of antiplagiarism is the translation values of Pancasila that highly uphold Intellectual Property Rights (IPR).
\end{abstract}

Keywords: plagiarism, antiplagiarism, organizational culture. 


\section{PENDAHULUAN}

Plagiarism merupakan salah satu bentuk pelanggaran akademik. Semua bentuk kecurangan akademik sangat merugikan universitas mana pun karena dapat merusak nama baik institusi dan integritas fakultas dan mahasiswa (Singh, 2016, p. 36). Plagiarisme umumnya juga dianggap sebagai kesalahan akademik yang serius dan sering dikaitkan dengan label penghukuman seperti penipuan, kecurangan, kejahatan akademis, ketidakjujuran intelektual, kegagalan moral, dan lain-lain (Hu \& Lei, 2015, p. 234). Secara sosial, plagiarism diartikan sebagai tindakan yang dikonstruksi secara budaya dan reaksi bawah sadar terhadap perbedaan mendasar nilai-nilai tentang peran individu dalam penciptaan pengetahuan (Leask, 2006, p. 183). Dalam paper ini plagiarisme didefinisikan sebagai tindakan atau praktik mengambil karya orang lain atau ide dan membagikannya sebagai milik sendiri.(Oxford English Dictionary, 2010)

Di negara maju seperti Jerman, istilah plagiarisme (Plagiat) tidak pernah dikutip secara literal dalam KUHP Jerman, karena para ahli hukum menganggapnya istilah seharihari untuk merujuk pada kasus hak cipta pelanggaran tertentu yang dipertimbangkan dalam Pasal 23 UU tentang Kekayaan Intelektual (Urheberrechtsgesetz), yang menyatakan bahwa persiapan atau jenis transformasi lainnya dari sebuah karya hanya dapat diterbitkan atau digunakan dengan izin dari pencipta asli (Ruipérez \& García-Cabrero, 2016, p. 10). Begitu pula di Indonesia, hukum Indonesia mengatur tentang hak cipta (intelectual property right) yang dicantumkan dalam Undang-Undang Nomor 19 tahun 2010(Mendiknas, 2010). Bagi siapa saja yang melanggar atau mencuri hak cipta orang lain akan dikenakan ancaman pidana dan ganti rugi material.

Meskipun hukum telah mengatur demikian, namun pelanggaran akademik masih banyak dilakukan. Beberapa kasus yang terjadi dan berimplikasi pada berhentinya karir akademisi maupun sanksi secara sosial yaitu, kasus plagiarisme tesis doktoral yang dilakukan oleh Menteri Pertahanan Jerman, Karl-Theodor zu Guttenberg, yang akhirnya harus mengundurkan diri (Ruipérez \& García-Cabrero, 2016, p. 9). Dari kasus ini kemudian Jerman menindaklanjutinya dengan menciptakan metode investigasi kolaboratif yang efektif terhadap plagiarism dalam tugas ilmiah dan akademik dengan menggunakan internet dan media sosial, yang disebut dengan "Vroni Plag" wiki. Ada pula "Ombudsman for Science" sebagai instrumen atau alat nasional yang digunakan untuk mencegah, mengatur dan memerangi ketidakjujuran ilmiah. Kemudian, menganalisis pengalaman dari negara Jerman dalam memberlakukan etika akademik dari perspektif sejarah yang selanjutnya pengalaman tersebut digunakan sebagai referensi negara-negara Eropa yang lain.

Kasus di negara lain yang tercatat pada tahun 1998 semua buku biografi Alexander Graham Bell karya seorang ahli sejarah Skotlandia, James A. Mackay, dipaksa ditarik dari peredaran, karena menyalin dari sebuah buku dari tahun 1973. Selain itu, ia juga dituduh memplagiat biografi Mary Queen of Scots, Andrew Carnegie, dan Sir William Wallace. Lalu di tahun 1999, ia juga harus menarik biografi John Paul Jones karena kasus yang sama. Kemudian, Stephen Ambrose, seorang ahli sejarah dikritik karena telah menggunakan dan mengambil banyak paragraf dari tulisan-tulisan orang lain. Dilanjutkan di tahun 2002, ia dituduh oleh dua penulis karena menyalin sebagian tulisannya yang membahas tentang pilot-pilot pesawat pembom dalam Perang Dunia II dari buku karya Thomas Childers, The Wings of Morning dalam bukunya The Wild Blue (Mashuri, 2016, p. 135). 
Sedangkan beberapa kasus di Indonesia yang mencuat ke public antara lain, kasus plagiat dalam disertasi Dr. Muhaimin yang dijadikan buku berjudul Bisnis dan Politik yang mirip dengan bukunya Richard Robison, Indonesia: The rise of Capital. Polemik kasus ini sampai kemeja hijau oleh pengusaha Probosutejo yang merasa nama baiknya dicemarkan dalam buku tersebut ( Fanany, 1992, p. 3). Kedua, kasus seorang Guru Besar di Universitas Riau, Prof.II (namanya dirahasiakan), terbukti melakukan plagiarisme dalam membuat buku yang berjudul, "Sejarah Maritim". Buku itu merupakan buku jiplakan dari buku Budaya Bahari karya Mayor Jendral (Marinir) Joko Pramono terbitan Gramedia, tahun 2005 (Koran Harian Kompas, 24/08/2011).

Ketiga, kasus plagiat Dr. Ipong S. Azhar, mahasiswa S3 UGM yang lulus dari Pascasarjana (S-3) UGM tahun 1998. Disertasi doktor Ipong disinyalir melakukan penjiplakan skripsi S-1 Moch. Nurhasyim, alumnus FISIP Unair Surabaya tahun 1996 (Koran Harian Republika,24/12/1999). Keempat, kasus plagiat Anggito Abimanyu dosen UGM yang pada saat itu menjabat sebagai Dirjen Penyelenggaraan Haji dan Umroh (PHU) Kementerian Agama. Artikel Anggito yang ditulisnya pada Koran Kompas 10 Februari 2014 yang berjudul "Gagasan Asuransi Bencana" di Rubrik Opini dinilai hampir sembilan puluh persen mirip dengan artikel yang pernah ditulis oleh Hotbonar Sinaga di koran yang sama yang dilansir pada 21 Juli 2006 dengan judul "Menggagas Asuransi Bencana". Anggito terbukti melakukan plagiat, karena terdapat banyak kesamaan dari segi judul maupun isi artikel tersebut. Pada kasus keempat ini berimplikasi luar biasa pada dicopotnya jabatan Anggito sebagai Dirjen Penyelenggaraan Haji dan Umroh (PHU) Kementerian Agama serta pengunduran dirinya sebagai dosen UGM ("Kasus plagiarisme, Anggito Abimanyu mundur dari UGM | merdeka.com," n.d.).

Berkaca dari semua masalah yang sudah dipaparkan diatas, dalam lingkungan akademik terdekat kita, banyak sekali kasus tidak terpublikasi yang merupakan praktik plagiat di perguruan tinggi, misalnya paper mahasiswa yang sebagian besar ditulis dengan cara copy paste, naskah skripsi yang hampir sama semua pada bagian metodologi penelitian, dan kasus-kasus pelanggaran lainnya. Melihat kasus-kasus tersebut, janganjangan plagiat sudah menjadi bagian dari budaya akademik kita? Atau bahkan ada sikap pembiaran pada tindakan tersebut yang kemudian beranggapan bahwa tindakan plagiat menjadi hal yang biasa dan tidak dipersoalkan. Bisa jadi pada saat melakukan plagiasi itu memang disengaja dan dalam keadaan sadar atau dikarenakan kurangnya pengetahuan dan sosialisasi penulisan karya ilmiah yang benar. Tingkat kesadaran mahasiswa yang rendah tentang plagiarism disebabkan oleh banyak dari mereka tidak mengerti apa itu plagiarisme? Mahasiswa mengakui bahwa mereka telah sengaja menjiplak tulisan orang lain tanpa menyebutkan sumbernya (Ramzan, Munir, Siddique, \& Asif, 2012, p. 74). Untuk itu, perlu adanya langkah konkrit yang harus segera dilakukan agar tindakan plagiat ini tidak mengakar pada budaya disebuah organisasi.

Dari hasil observasi (25/08/2018) peneliti melihat ada yang menarik di lingkungan pascasarjana UIN Sunan Kalijaga Yogyakarta. Dibeberapa sudut tempat terdapat sloganslogan dalam bentuk poster permanen maupun stiker yang menyatakan penolakan terhadap tindakan plagiarisme. Poster-poster tersebut dalam bingkai budaya organisasi mengindikasikan sebuah upaya institusi untuk menolak plagiarism sebagai bagian dari budaya organisasinya. Karena unsur budaya organisasi terdiri dari 3 hal, yaitu artefak, espoused valuel enacted behavior dan asumsi dasar yang dipercaya (Kreitner \& Kinicki, 2010). Maka, peneliti ingin mengkaji lebih detail tentang budaya organisasi anti plagiarism 
yang dilakukan dan disosialisasikan di pascasarjana UIN Sunan Kalijaga Yogyakarta. Mengingat bahwa program pascasarjana diharapkan mampu menjadi leading sector kegiatan akademik berbasis riset dan publikasi ilmiah. Pada akhirnya, untuk tujuan ini universitas dan institut pendidikan tinggi didirikan tidak hanya menghasilkan ide, teori, formula dan standar baru melalui percobaan, kerja lapangan dan melalui metode penelitian lain, tetapi juga menghasilkan lulusan yang terampil dan kompeten dengan standar kejujuran, etika dan profesionalisme yang tinggi untuk melayani masyarakat (Ramzan et al., 2012, p. 74).

\section{METODE}

Penelitian ini menggunakan pendekatan kualitatif yang disebut juga dengan pendekatan investigasi. Pengambilan data dilakukan dengan bertatap muka dan berinteraksi langsung dengan orang-orang yang berada di lingkungan penelitian.(James H \& Sally, 2003) Data yang digunakan dalam penelitian ini meliputi data primer dan data sekunder. Data primer diperoleh melalui indept interview dengan mahasiswa, staff, dosen, dan pejabat di lingkungan pascasarjana UIN Sunan Kalijaga Yogyakarta. Wawancara digunakan untuk menggali dan mendapatkan data informasi tentang espoused value/ enacted behavior (nilai yang dianut dan perilaku yang ditetapkan, nilai-nilai antara yang tertulis dan yang dilaksanakan) seperti apa yang melandasi perilaku mahasiswa dan dosen dipascasarjana UIN Sunan Kalijaga Yogyakarta terkait anti plagiarism dan asumsi dasar yang dipercaya pascasarjana UIN Sunan Kalijaga Yogyakarta untuk menanggulangi plagiarism.

Sedangkan data sekunder diambil dari buku-buku acuan terkait seperti panduan akademik, student handbook, surat keputusan para pemangku kebijakan universitas/fakultas dan sumber-sumber terkait lain yang dapat dikembangkan datanya. Dari buku acuan tersebut dapat diketahui kebijakan-kebijakan atau peraturan-peraturan yang ditetapkan dan ditegakkan pascasarjana UIN Sunan Kalijaga Yogyakarta dalam menanggulangi tindakan plagiarism. Kedua data di atas juga didukung dengan data hasil observasi. Selama pengamatan, posisi peneliti sebagai peserta tanpa keterlibatan langsung dengan peserta yang diteliti(Merriam, 2009). Catatan lapangan yang terperinci dicatat oleh peneliti ketika pengamatan dilakukan. Secara sistematis data yang dihasilakan dari pengamatan disempurnakan dan dielaborasi segera untuk menyimpan sebanyak mungkin informasi yang diamati. Observasi dilakukan untuk mendapatkan data informasi mengenai artefak-artefak yang menggambarkan gerakan antiplagiarism di lingkungan pascasarjana.

Analisis penelitan ini menggunakan pendekatan kualitatif. Wawancara mendalam dilakukan dengan menggunakan pertanyaan yang telah dipersiapkan sebelumnya (semistructured interview). Pertanyaan dapat berkembang tetapi tetap dalam garis besar daftar pertanyaan yang telah ditentukan sebelum proses penelitian. Wawancara direkam dengan menggunakan voice recorder yang kemudian disusun dalam transkrip dan dilanjutkan dengan proses koding data barulah kemudian disusun dalam sebuah laporan hasil penelitian (Miles, M. B., \& Huberman, A. M., 1984). 


\section{KERANGKA KONSEPTUAL}

\section{Plagiarisme}

Sebelum masuk lebih jauh meneliti tentang budaya organisasi yang dianut oleh pascasarjana UIN Sunan Kalijaga Yogyakarta dalam menyikapi plagiarisme, perlu dibahas lebih dahulu apa sebenarnya yang disebut dengan plagiarisme. Menurut Peraturan Menteri Pendidikan Nasional Nomor 17 Tahun 2010 Pasal 1 ayat 1, plagiarism didefinisikan sebagai berikut:

"perbuatan secara sengaja atau tidak sengaja dalam memperoleh atau mencoba memperoleh kredit atau nilai untuk suatu karya ilmiah, dengan mengutip sebagian atau seluruh karya dan/atau karya ilmiah pihak lain yang diakui dengan karya ilmiahnya, tanpa menyatakan sumber secara tepat dan memadai”(Mendiknas, 2010).

Menurut Swales dan Feak, plagiarisme didefinisikan sebagai sebuah kegiatan sadar menyalin atau meminjam istilah orang lain tanpa menyebutkan sumber atau penulis aslinya (Swales, J. M. \& Feak, C. B, 2009). Kegiatan yang dapat dikategorikan plagiat antara lain: 1. Menyalin sebuah paragraf sama persis seperti aslinya tanpa menyebutkan sumbernya. 2. Meng-copy/menyalin sebuah paragraf dengan mengubahnya sedikit, misalnya dengan mengubah beberapa kata dengan sinonimnya.

3. Meng-cut dan paste sebuah paragraf menggunakan kalimat seperti aslinya tetapi dengan membuang beberapa kata di dalamnya, atau dengan menambahkan beberapa kalimat.

Definisi di atas ditegaskan lebih detail dalam Peraturan Menteri Pendidikan Nasional RI Nomor 17 Tahun 2010 tentang Penanggulangan Plagiat di Perguruan Tinggi, terutama pada Bab II mengenai Lingkup dan Pelaku. Sebagai tindakan pencegahan, Peraturan Menteri tersebut mewajibkan bagi setiap pimpinan Perguruan Tinggi untuk mengunggah semua karya ilmiah dosen, peneliti, mahasiswa, dan tenaga kependidikan melalui portal GARUDA (Garda Rujukan Digital). Portal ini nantinya akan dapat menjadi data base bagi hasil-hasil penelitian di Indonesia dan pada gilirannya bisa menjadi detektor plagiarisme itu sendiri.

Terjadinya plagiarisme dapat dipengaruhi oleh beberapa faktor. Menurut hasil penelitian Forgas dan Negre setidaknya ada tiga faktor yang mempengaruhi tindakan plagiat, yaitu:

1. Aspek mahasiswa, antara lain karena jeleknya manajemen waktu yang dimiliki oleh mahasiswa tersebut, terlalu banyaknya tugas yang diberikan kepada mahasiswa serta kekurangsiapan mahasiswa mengerjakan tugas-tugasnya;

2. Adanya kesempatan yang disediakan oleh kemajuan ICT (teknologi informasi dan komunikasi);

3. Aspek terkait dengan dosen serta subjek mata kuliah yang diajarkan, misalnya terlalu teoritis (Forgas, R. C \& Negre, J. S, 2010).

Hal-hal yang temasuk dalam tindakan plagiarism adalah mengakui tulisan, gagasan, karya kelompok orang lain sebagai tulisan sendiri, menyajikan tulisan yang sama dalam kesempatan yang berbeda tanpa menyebutkan asal-usulnya, meringkas dan memparafrasekan (mengutip tak langsung) tanpa menyebutkan sumbernya, ataupun 
meringkas dan memparafrasekan dengan menyebut sumbernya, tetapi rangkaian kalimat dan pilihan katanya masih terlalu sama dengan sumbernya.

\section{Plagiarisme dalam Budaya Organisasi}

Menurut Robbins dan Judge budaya organisasi mengacu pada suatu sistem berbagi arti yang dilakukan oleh para anggota yang membedakan organisasi dari organisasi lain (Robbins, Judges, 2016, p. 355). Dari budaya yang sudah terbentuk perlu mentransmisikan kepada para anggota organisasi dalam beberapa bentuk, yang paling potensial adalah melalui cerita, ritual, simbol material, dan bahasa.

Budaya organisasi merupakan perangkat sistem nilai-nilai (values), keyakinankeyakinan (beliefs), asumsi-asumsi (assumptions), atau norma-norma yang telah lama berlaku, disepakati dan diikuti oleh para anggota suatu organisasi sebagai pedoman perilaku dan pemecahan masalah-masalah organisasinya Lebih jelasnya, budaya organisasi merupakan sosialisasi dan internalisasi nilai dalam menggerakkan seluruh anggota organisasi untuk melakukan tugas-tugasnya. Bagi para anggota, mau tidak mau akan mengikuti budaya yang berlaku dalam organisasi tersebut agar bisa diterima dalam lingkungan tempatnya bekerja (Sutrisno, 2010, p. 20).

Sebagaimana yang telah dijelaskan sebelumnya, definisi plagiat ini akan dilihat dalam konteks budaya organisasi yang diterapkan pada pascasarjana UIN Sunan Kalijaga Yogyakarta. Konsep budaya organisasi dalam Kreitner dan Kinicki diambil dari teori Schein tentang Corporate Culture, yang sering diartikan sebagai budaya perusahaan. Budaya organisasi mencakup tiga tingkat, yaitu:

1. Artefak yang kasat mata, yang terdiri dari manifestasi fisik sebuah budaya organisasi;

2. Espoused value dan enacted behavior sebagai nilai yang dianut dan perilaku yang ditetapkan, nilai-nilai antara yang tertulis dan yang dilaksanakan, serta

3. Asumsi dan nilai-nilai dasar yang dipercayai oleh sebuah organisasi (Kreitner \& Kinicki, 2010, pp. 65-66).

Ketiga hal tersebut akan digunakan sebagai kerangka dasar untuk mengkaji budaya organisasi anti plagiarisme yang dilakukan di pascasarjana UIN Sunan Kalijaga Yogyakarta.

\section{HASIL PENELITIAN DAN PEMBAHASAN}

\section{Menyamakan Persepsi tentang Plagiarisme}

Dari hasil wawancara yang sudah dilakukan dengan pimpinan, dosen, mahasiswa, dan karyawan di pascasarjana UIN Sunan Kalijaga Yogyakarta didapatkan beragam persepsi mengenai plagiarisme. Menurut direktur pascasarjana, plagiarism adalah mencuri pikiran, tulisan, dan ide orang lain dan mengakuinya sebagai karya sendiri. Menurutnya, dalam menanggulangi tindakan plagiarism perlu keseriusan mengajar dan membimbing mahasiswa serta pemberlakuan secara ketat checker plagiarism pada karya mahasiswa. Komitmen ini yang selalu ditegakkan dikalangan dosen dan staff akademik (Wawancara, 9/9/2018). 
Menurut seorang dosen, plagiarisme itu sebenarnya ada tingkatan-tingkatannya. Mulai dari mengambil tulisan (copy-paste), sampai pada mencuri ide tanpa menyebutkan sumber referensinya meskipun sudah melakukan pharafrase. Tindakan plagiarism dalam proses perkuliahan, tidak mungkin bisa terdeteksi dengan jelas pada paper yang dipresentasikan setiap mahasiswa. Dosen harus mencari alternative tugas yang lain agar mahasiswa tidak terjebak dalam plagiarism. Misalnya, resensi atau review buku terbaru, menerjemahkan buku asing, atau membuat laporan pengamatan lapangan. Dosen juga harus memahami bahwa membuat paper itu tidak mudah. Jika setiap mata kuliah itu membuat paper maka kondisi mahasiswa bisa memungkinkannya untuk mengambil jalan pintas yaitu plagiat (Wawancara, 10/9/2018).

Hasil wawancara dengan mahasiswa, mereka berpendapat plagiasi adalah tindakan menduplikasi karya orang lain baik berupa narasinya maupun idenya. Pada intinya, mahasiswa memahami bahwa plagiarism itu adalah mengambil alih ide pikiran orang lain tanpa menyertakan sumber kutipannya. Menurutnya, beragam dosen memiliki standar masing-masing dalam penegakan antiplagiarisme. Masih ada juga salah satu dosen yang tidak memperdulikan dan menerima makalah yang asal-asalan. Ada pula dosen yang masih menerima paper hasil pharafrase dan kebanyakan dosen yang ketat dan sangat gigih menolak segala bentuk plagiat. Pada saat mahasiswa diketahui papernya plagiat, dosen tersebut tidak segan-segan membuangnya ketempat sampah dan mencerca mahasiswa tersebut "tidak memiliki performa akademik". Dosen ini menghindari tugas paper kelompok. Semua paper presentasi harus dilakukan secara individu. Penilaian dosen akan sangat menghargai dan mengapresiasi hasil paper mahasiswa yang narasi dan struktur tulisannya berbeda sebagai bentuk kreatifitas (Wawancara, 4/10/2018).

Penolakan program pascasarjana terhadap tindakan plagiarism sudah sangat dipahami oleh semua anggota sivitas akademik, mulai dari pimpinan, dosen, mahasiswa, dan karyawan. Menurut mahasiswa, kultur akademik sudah terbentuk untuk bersama-sama menolak segala bentuk plagiarism. Pascasarjana sudah melakukan sosialisasi kegiatan akademik secara massif dan terbuka sehingga seluruh kalangan akademisi mengetahui dan melaksanakan norma-norma kegiatan akademik tersebut, terutama mengenai budaya organisasi antiplagiarisme. Sosialisasi yang kontinyu ini sudah menjadi kultur dan tradisi akademik yang kuat.

\section{Budaya Organisasi Anti Plagiarisme}

Penelitian ini menggali informasi tentang budaya organisasi antiplagiarism di Pascasarjana Universitas Islam Negeri (UIN) Sunan Kalijaga Yogyakarta. Budaya organisasi yang dikaji mencakup tiga tingkat, yaitu:

Artefak

Disebut artefak karena merupakan segala sesuatu yang kasat mata. Sesuatu itu yang terdiri dari manifestasi fisik sebuah budaya organisasi. Misalnya slogan lembaga tentang budaya antiplagiarisme yang dimanifestasikan dalam bentuk stiker dan banner yang ditempatkan ditempat-tempat strategis agar dapat dengan mudah dilihat oleh banyak orang. Sebagaimana hasil pengamatan peneliti yang dilakukan di lingkungan pascasarjana UIN Sunan Kalijaga Yogyakarta telah mendapatkan 5 temuan artefak sebagai berikut: 


\section{Stiker 1}

Terdapat dua stiker (gambar 1 dan gambar 2) yang ditempelkan di dua papan pengumuman milik pascasarjana UIN Sunan Kalijaga Yogyakarta. Stiker ini berbunyi: "ANDA MEMASUKI KAWASAN ANTI-PLAGIARISME. Plagiarisme adalah kejahatan akademik yang diancam dengan sanksi yang tercantum dalam Permendiknas No. 17 Tahun 2010 tentang pencegahan dan penanggulangan plagiat di Perguruan Tinggi (pasal 12 dan 13)".

Pada stiker ini juga terdapat simbol lingkaran dan garis stop pada gambar paper yang tertulis kata "paste". Simbol ini menunjukkan tentang sikap penolakan terhadap tindakan copy paste dari lembaga pascasarjana UIN Sunan Kalijaga Yogyakarta.

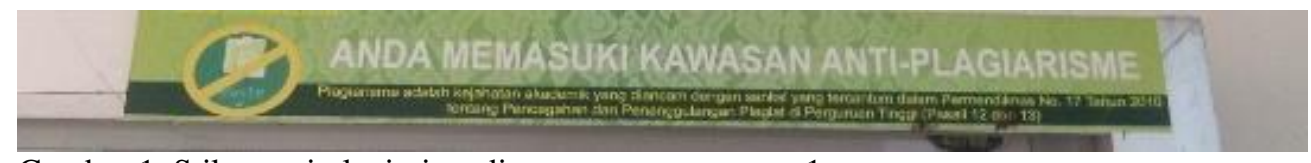

Gambar 1. Stiker anti plagiarism di papan pengumuman 1

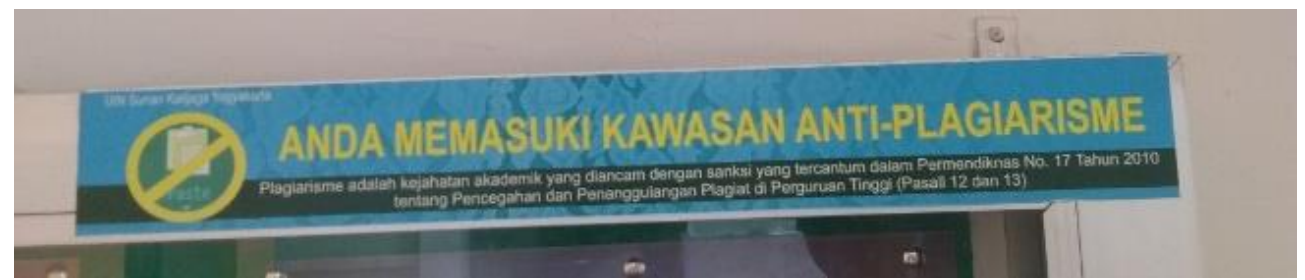

Gambar 2. Stiker anti plagiarism di papan pengumuman 2

\section{Stiker 2}

Redaksi di slogan pada gambar 3 dan gambar 4 berbeda dengan slogan pada stiker sebelumnya. Meski terdapat kesamaan redaksi pada definisi plagiarism. Secara jelasnya, redaksi pada stiker kedua adalah sebagai berikut: "Hari gini plagiat?. Plagiarisme adalah kejahatan akademik yang diancam dengan sanksi yang tercantum dalam Permendiknas No. 17 Tahun 2010 tentang pencegahan dan penanggulangan plagiat di Perguruan Tinggi (pasal 12 dan 13)".

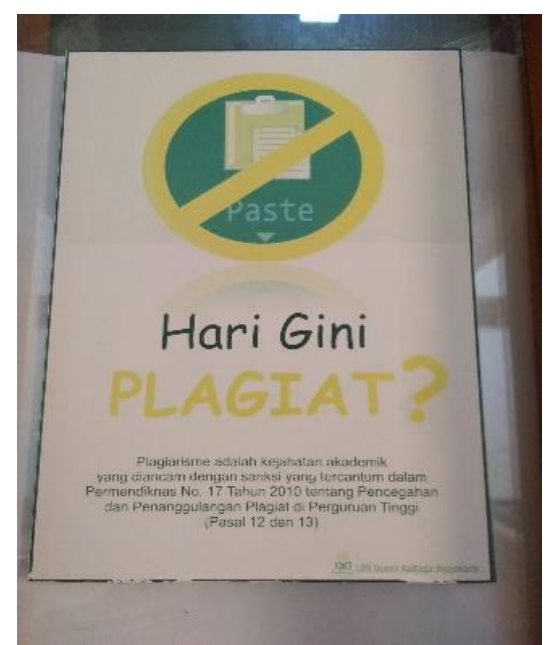

Gambar 3. Stiker penolakan terhadap plagiarism 


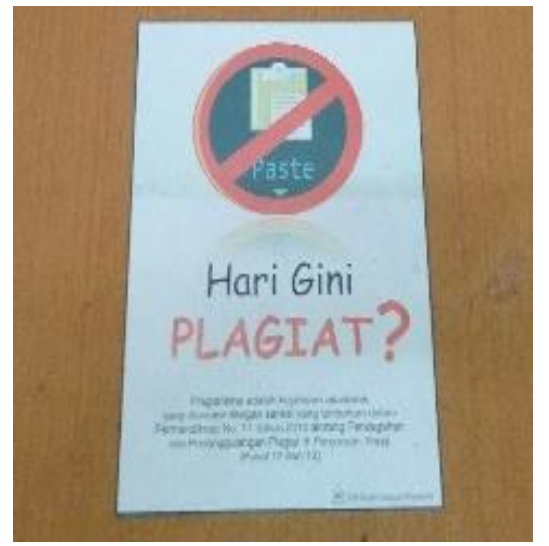

Gambar 4. Stiker penolakan terhadap plagiarism 2

\section{Tempelan kaca tentang Plagiarisme}

Slogan berikutnya yang dituliskan pada kaca yang ditempelkan di tembok tangga menuju lantai 2 gedung pascasarjana UIN Sunan Kalijaga Yogyakarta. Slogan itu berbunyi: "TURN BACK PLAGIARISM". Tulisan itu semua tertulis dengan huruf kapital. Slogan yang tertulis dengan huruf kapital diindikasikan terdapat penekanan yang sungguh-sungguh untuk menegakkan budaya antiplagiarisme.

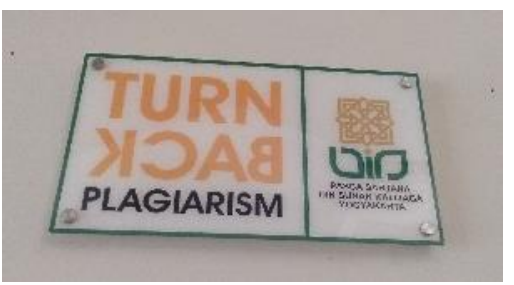

Gambar 5. Stiker penolakan terhadap plagiarism

Kata "turn back" diberi warna orange yang menyala. Siapapun orang yang melintasi tangga akan secara langsung tertarik perhatiannya pada tempelan dinding ini. Artefak ini bertujuan untuk memberikan pandangan kepada seluruh sivitas akademik dilingkungan pascasarjana UIN Sunan Kalijaga Yogyakarta baik dari pimpinan, dosen, staff dan mahasiswa untuk menjaga dan melestarikan budaya akademik antiplagiarisme.

Kata "back" tertulis secara terbalik. Hal ini mengadopsi dari tulisan Turn Back Crime. Bentuk penulisan kata yang sudah sangat familiar di masyarakat pada umumnya. Dari penulisan bentuk seperti ini diharapkan dapat mempengaruhi seseorang bahwa tindakan plagiarism itu sama dengan tindakan kriminal yang dapat diproses secara hukum negara. Sebagaimana dalam Permendiknas No. 17 Tahun 2010 tentang pencegahan dan penanggulangan plagiat di Perguruan Tinggi (pasal 12 dan 13).

Dari penjelasan di atas, maka dapat didasarkan pada beberapa konsep definisi penulisan poster beserta tujuannya berikut ini:

1. Poster adalah alat untuk mengimbau, memberitahu atau mengumumkan melalui tulisan dan biasanya dilengkapi dengan gambar. Gambar dipesan sesuai tujuan dari tulisan yang dibuat. Poster adalah media untuk menyampaikan pesan kepada pembaca dengan jelas melalui susunan kata-kata dan gambar. Poster juga berfungsi sosial, sebab dapat mempengaruhi masyarakat dari tingkah laku atau tindakannya dalam kegiatan sehari-hari dalam suasana yang bersifat umum (Bari, 2011, p. 11). 
2. Hasnun mengungkapkan bahwa poster merupakan gambar atau tulisan di atas kertas atau kain yang dipasang di tempat umum berisi pemberitahuan. Hasnun menambahkan, isi dan tujuan poster beragam. Ada poster yang berisi imbauan kepada masyarakat tentang suatu kegiatan. Ada juga poster yang berisi larangan untuk menghindari perbuatan tertentu. Misalnya poster tentang bahaya narkoba, baik melalui kata-kata maupun gambar. Ada juga poster yang berisi ajakan agar masyarakat mau membeli barang tertentu atau menghadiri acara tertentu (Hasnun, 2006, p. 253).

Tujuannya dapat disimpulkan bahwa pemasangan poster, stiker, dan tempelan yang bertuliskan slogan tersebut merupakan sebuah proses pembentukan budaya akademik antiplagiarisme di UIN Sunan Kalijaga Yogyakarta.

\section{Espoused Values}

Espoused value dalam budaya akademik merupakan nilai yang dianut dan perilaku yang ditetapkan. Nilai-nilai ini yang harus disesuaikan antara yang tertulis dan yang dilaksanakan. Maka dari itu, sebuah organisasi maupun anggota organisasi memerlukan tuntunan strategi, tujuan dan filosofi dari pemimpin organisasi untuk bersikap dan bertindak. Hasil wawancara dengan direktur pascasarjana, didapatkan data bahwa nilainilai yang dianut oleh pascasarjana dalam membentuk budaya organisasi antiplagiarisme adalah penegakan nilai yang didasarkan pada peraturan Menteri Pendidikan tentang plagiarism dan peraturan yang mengadopsi dari Kementerian Riset Teknologi dan Pendidikan Tinggi (Wawancara, 5/10/2018).

Secara umum, pemerintah telah mengatur pencegahan dan penanggulangan plagiarisme di Indonesia dengan diterbitkannya Peraturan Menteri Nomor 17 Tahun 2010 dan Undang-Undang Nomor 19 Tahun 2002 tentang Plagiarisme. Di dalam Peraturan Menteri ini sudah dibahas secara komprehensif, mulai dari definisi, lingkup dan pelaku, tempat dan waktu, pencegahan, penanggulangan, sanksi, serta pemulihan nama baik terkait dengan praktik plagiarisme. Undang-Undang Nomor 20 Tahun 2003 tentang Sistem Pendidikan Nasional pasal 25 ayat 2 disebutkan bahwa lulusan perguruan tinggi yang karya ilmiahnya digunakan untuk memperoleh gelar akademik, profesi atau vokasi, yang terbukti merupakan jiplakan dicabut gelarnya atau dipidana dengan pidana penjara paling lama 2 tahun dan/atau pidana denda paling banyak Rp. 200.000.000,- (200 juta rupiah) (Mendiknas, 2010).

Pada ruang lingkup perguruan tinggi, Peraturan Pemerintah Nomor 153 Tahun 2000 pasal 15 ayat 1, tentang Tugas Senat Akademik, universitas memiliki lembaga Senat Akademik yang menyusun kebijakan penilaian prestasi dan etika akademik, kecakapan, serta integritas kepribadian civitas akademika, yang salah satu penerapannya menjaga mutu akademik dengan mengatur agar mahasiswa selalu menjaga etika akademik melalui aturan tentang plagiarisme dan ethical misconduct.

Pada tataran lebih khusus, program pascasarjana UIN Sunan Kalijaga Yogyakarta menyusun Student Handbook yang diberikan kepada setiap mahasiswa baru sebagai panduan tentang penyelenggaraan akademik. Dalam salah satu penjelasannya, Student Handbook memuat secara spesifik tentang ketentuan mahasiswa untuk membuat dan menandatangani lembar bermaterai tentang keaslian karya yang bebas dari tindakan plagiarism. Peraturan tertulis tentang kebijakan plagiarisme ini menunjukkan keseriusan 
pascasarjana UIN Sunan Kalijaga Yogyakarta dalam menindak tindakan tersebut. Karena barangsiapa yang terbukti melakukan plagiasi maka harus siap menerima sanksinya. Dalam lembar persetujuan tesebut menjadi ketetapan hitam di atas putih sebagai dasar penolakan terhadap plagiarism. Maka, dari awal pihak pascasarjana harus mensosialisasikannya kepada mahasiswa, agar pelanggaran scientific dan tindakan plagiat dapat dihindari (Malgwi \& Rakovski, 2009).

Bentuk yang lain, juga ditunjukkan oleh pascasarjana UIN Sunan Kalijaga Yogyakarta tentang pemberlakuan checker plagiarism sebelum mahasiswa melaksanakan ujian komprehensif, ujian proposal, dan ujian munaqasyah tesis/ disertasi. Agar mahasiswa dapat melaksanakan ujian munaqasyah harus memenuhi syarat tingkat similarity atau plagiasinya dibawah $20 \%$. Kalau masih di atas $20 \%$ maka mahasiswa tersebut harus memperbaikinya/ merevisinya. Contoh pemberlakuan checker plagiarism di pascasarjana UIN Sunan Kalijaga Yogyakarta seperti pada gambar 6 dan gambar 7.

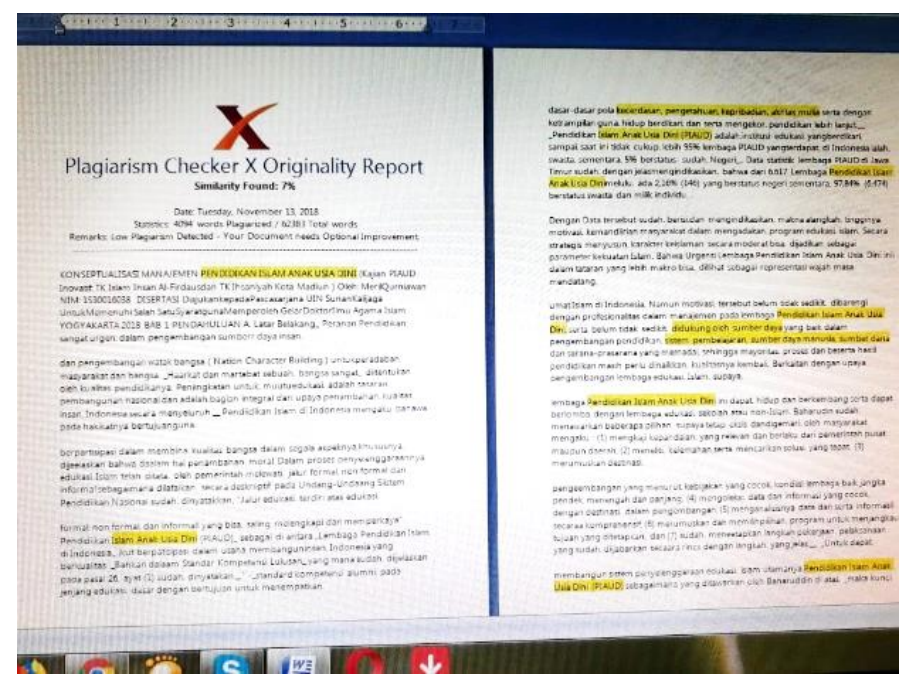

Gambar 6. Artikel setelah diperiksa dengan plagiarism checker

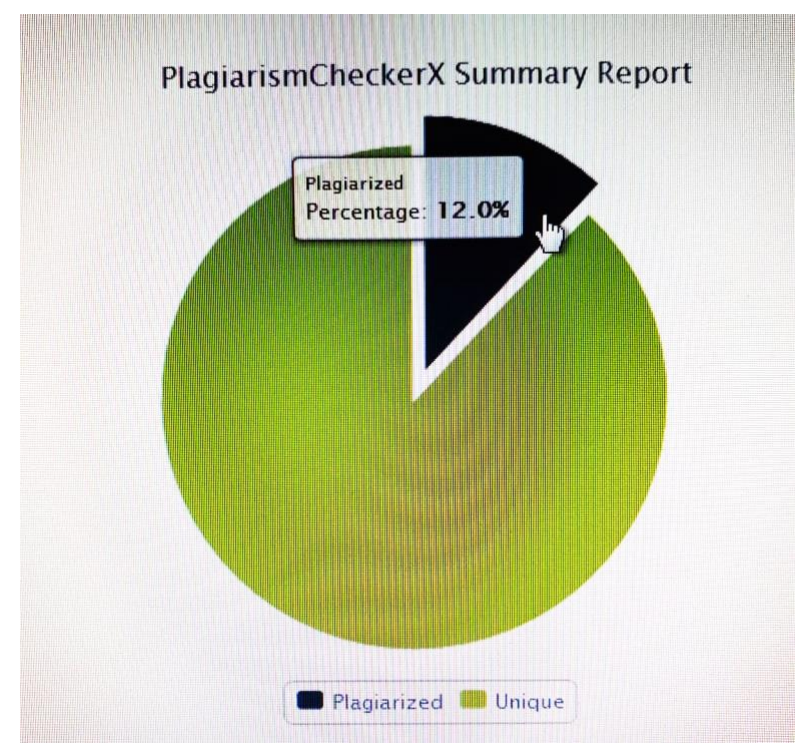

Gambar 7. Hasil prosentase dari plagiarism checker 
Gambar 6 dan gambar 7 menjadi bukti penolakan pascasarjana UIN Sunan Kalijaga Yogyakarta terhadap tindakan Plagiarisme. Bukti checker plagiarism tersebut biasanya difoto dan disebar oleh staff akademik di group mahasiswa. Dengan demikian, secara tidak langsung mahasiswa akan terbentuk sebuah budaya akademik antiplagiarisme yang kokoh. Karena konsekuensi bagi pelaku plagiarism lebih pada sanksi sosial.

\section{Enacted Behaviors}

Untuk mengetahui perilaku yang ditunjukkan mahasiswa terhadap plagiarisme kami melakukan wawancara dengan beberapa mahasiswa. Menurut beberapa mahasiswa Pascasarjana yang kami wawancara, plagiarisme harus dihindari oleh mahasiswa karena merupakan tindakan yang tidak terpuji. Pengetahuan tentang plagiarisme sudah disosialisasikan oleh Program Pascasarjana UIN Sunan Kalijaga Yogyakarta pada waktu stadium general mahasiswa baru. Walaupun demikian masih ada beberapa mahasiswa yang belum memahami sepenuhnya tentang plagiarisme. Terbukti masih adanya mahasiswa yang melakukan pelanggaran terhadap tindakan plagiarisme tersebut. Sanksi yang pernah diberikan kepada mahasiswa tersebut yaitu tidak diberikannya nilai akhir sehingga mahasiswa harus mengulang mata kuliah.

Bagaimanakah sikap yang dilakukan jika dalam penyusunan paper atau tugas mengetahui temannya melakukan plagiarism? Berdasarkan wawancara yang kami lakukan, mahasiswa tersebut hanya akan mengingatkan mahasiswa yang melakukan tindakan plagiarisme tersebut dan menunjukkan bagaimana cara membuat paper atau tugas yang benar. Mahasiswa yang mengetahui juga tidak akan melaporkan kepada dosen. Pelanggaran tersebut tidak disadari oleh pelaku plagiasi karena mereka tidak mengetahui secara benar tentang cara-cara penulisan ilmiah, termasuk bagaimana cara mengutip maupun memparaphrase yang benar.

Asumsi dan Nilai-nilai Dasar

UIN Sunan Kalijaga Yogyakarta didirikan sebagai salah satu pilar kemerdekaan bangsa. Dengan mengemban misi kebangsaan dan kerakyatan seluruh civitas akademika UIN diharapkan untuk selalu menjunjung tinggi nilai perjuangan untuk meningkatakan martabat bangsa Indonesia. Para founding father menitipkan Pancasila sebagai dasar-dasar kerakyatan agar terpelihara dan senantiasa menjadikan manusia Indonesia yang unggul, mandiri dan bermartabat demi kemakmuran bangsa dan negara. Salah satu penjabaran nilainilai Pancasila adalah menghargai hasil karya orang lain (sila 5 butir 11). Sehingga pengakuan atas HAKI itu harus dijunjung tinggi bukan saja pada tataran konsep tetapi juga harus dihayati dan dilaksanakan dalam kehidupan sehari-hari.

Perlu disadari pula bahwa kebebasan otonomi dan kultur akademik adalah hak milik yang paling berharga sebuah perguruan tinggi. Hak milik ini menyadarkan kalangan akademisi tentang misi Undang-Undang nomor 20 tahun 2003 tentang Sistem Pendidikan Nasional dan PP nomor 61 tahun 1999 tentang perguruan tinggi negeri sebagai badan hukum. Landasan konstitusional ini harus dijadikan nilai yang terus dijaga, dibangun dan dikembangkan secara terencana, terarah, sistematis, dan berkesinambungan karena perguruan tinggi penting untuk memiliki karakteristik khusus agar menjadi panutan pihak luar. 


\section{SIMPULAN}

Tiga tingkat budaya organisasi yaitu artefak, espoused value dan enacted behavior, serta asumsi dan nilai-nilai dasar yang dipercayai organisasi, sudah ada pada pascasarjana UIN Sunan Kalijaga Yogyakarta. Bentuk sosialisasi pascasarjana mengenai penolakannya terhadap plagiarism ditunjukkan pada slogan-slogan stiker dan tempelan dinding pada tempat-tempat strategis yang bisa jelas dilihat orang banyak. Kampanye budaya organisasi antiplagiarisme ini menjadi kesan awal orang yang memasuki lingkungan pascasarjana secara langsung paham bahwa kawasan ini bebas dari praktek tindakan plagiat dan menjunjung tinggi integritas akademik.

Dari stiker tersebut juga sudah menyiratkan pengertian plagiarism beserta dengan peraturan perundanga-undangan dan sanksinya. Terlebih lagi, pascasarjana juga sudah memiliki instrumen pengecek plagiasi. Kemudian lebih jelasnya, kultur akademik menjadi terbentuk karena pemahaman seluruh anggota organisasi untuk tidak melakukan plagiasi. Pemahaman tentang norma-norma akademik ini dapat dipahami sebagai hasil dari proses belajar dan latihan di pascasarjana. Kemudian, dapat menginternalisasikan nilai pada diri pribadi agar menghindari hal-hal yang dilarang. Yang paling penting lagi, dari berbagai upaya dan usaha yang dilakukan pascasarjana terlihat dengan jelas bahwa pascasarjana telah memiliki komitmen yang kuat dalam menegakkan budaya organisasi antiplagiarisme.

Espoused Value dan enacted behavior dalam Budaya Akademik yang ditunjukkan Program Pascasarjana UIN Sunan Kalijaga Yogyakarta dalam Menyikapi Plagiarisme adalah memberlakukan kebijakan checker ILplagiarism dan ketentuan peraturannya dijelaskan pada student book. Student Handbook memuat secara spesifik tentang ketentuan mahasiswa untuk membuat dan menandatangani lembar bermaterai tentang keaslian karya yang bebas dari tindakan plagiarism. Adapun bukti hasil checker plagiarism dari tulisan mahasiswa yang berupa foto disebar oleh staff akademik di group mahasiswa. Dengan upaya ini, kesadaran tentang budaya organisasi antiplagiarism secara tidak langsung dapat dipahami oleh mahasiswa. Bentuk konsekuensi bagi pelaku plagiarism lebih pada sanksi sosial. Sedangkan, asumsi dan nilai-nilai yang mendasari UIN Sunan Kalijaga Yogyakarta untuk menolak tindakan plagiarism adalah nilai pancasila dalam menghargai hasil karya orang lain (sila 5 butir 11). Sehingga pengakuan atas HAKI itu harus dijunjung tinggi bukan saja pada tataran konsep tetapi juga harus dihayati dan dilaksanakan dalam kehidupan sehari-hari.

\section{DAFTAR PUSTAKA}

Bari. (2011). Desain Poster Pencemaran Udara untuk Pelestarian Lingkungan (Skripsi). Semarang: Universitas Negeri Semarang.

Edy Sutrisno. (2010). Budaya Organisasi. Jakarta: Kencana.

Forgas, R. C, \& Negre, J. S. (2010). Academic Plagiarism: Explanatory Factors from Student Perspective. 8. Hasnun, A. (2006). Pedoman Menulis untuk Siswa SMP dan SMA. Yogyakarta: Andi.

Hu, G., \& Lei, J. (2015). Chinese University Students' Perceptions of Plagiarism. Ethics \& Behavior, 25(3), 233-255. https://doi.org/10.1080/10508422.2014.923313

Ismet Fanany. (1992). Plagiat-Plagiat Di MIT Tragedi Akademis Di Indonesia. CV Masagung. James H, M., \& Sally, S. (2003). Research in Education. New Jersey: Pearson. 
Kasus plagiarisme, Anggito Abimanyu mundur dari UGM|merdeka.com. (n.d.). Retrieved February 8, 2019, from https://www.merdeka.com/peristiwa/kasus-plagiarisme-anggito-abimanyu-mundur-dariugm.html

Kreitner, \& Kinicki. (2010). Organizational Behavior ninth Edition. McGraw-Hill: Irwins.

Leask, B. (2006). Plagiarism, cultural diversity and metaphor-Implications for academic staff development. Assessment \& Evaluation in Higher Education, 31(2), 183-199. https://doi.org/10.1080/02602930500262486

Malgwi, C. A., \& Rakovski, C. C. (2009). Combating Academic Fraud: Are Students Reticent about uncovering the Covert? Journal of Academic Ethics, 7, 207-221.

Mashuri, I. (2016). Peran Perpustakaan Dalam Mengurangi Plagiarisme. Pustakaloka, 5(1), 135-142. https://doi.org/10.21154/pustakaloka.v5i1.490

Mendiknas. (2010). Peraturan Menteri Pendidikan Nasional RI nomor 17 tentang penanggulangan plagiat di Perguruan Tinggi.

Merriam, S. B. (2009). Qualitative Research: A Guide to Design and Implementation. San Francisco, CA: Jossey-Bass.

Miles, M. B., \& Huberman, A. M. (1984). Qualitative Data Analysis. London: Sage.

Oxford English Dictionary. (2010). Plagiarism. Retrieved from http://www.oed.com/view/Entry/144939.

Ramzan, M., Munir, M. A., Siddique, N., \& Asif, M. (2012). Awareness about plagiarism amongst university students in Pakistan. Higher Education, 64(1), 73-84. https://doi.org/10.1007/s10734-011-9481-4

Robbins, \& Judges. (2016). Perilaku Organisasi. Jakarta: Salemba Empat.

Ruipérez, G., \& García-Cabrero, J.-C. (2016). Plagiarism and Academic Integrity in Germany. Comunicar, 24(48), 9-17. https://doi.org/10.3916/C48-2016-01

Singh, S., School of Computing, University of South Africa, Roodepoort, South Africa, Remenyi, D., \& School of Computing, University of South Africa, Roodepoort, South Africa. (2016). Plagiarism and ghostwriting: The rise in academic misconduct. South African Journal of Science, Volume 112(Number 5/6). https://doi.org/10.17159/sajs.2016/20150300

Swales, J. M., \& Feak, C. B. (2009). Academic Writing for Graduate Students Essential Task and Skills Second Edition. Ann Arbors: The University of Michigan Press. 